\title{
Inelastic dynamic analysis and non-linear static analysis of 6- and 17-story RC buildings of ductile frames designed in Mexico City
}

\author{
J. A. Avila ${ }^{1,2}$ \\ ${ }^{I}$ Institute of Engineering, National University of Mexico \\ (UNAM), Mexico \\ ${ }^{2}$ Faculty of Engineering, National University of Mexico \\ (UNAM), Mexico
}

\begin{abstract}
A non-linear static analysis with monotonically increasing lateral loads was performed for two RC buildings with 6 and 17 stories, respectively, in order to compare their response against the results obtained from inelastic seismic analyses for the SCT-EW-85 record. The buildings are located in compressible seismic zone $\mathrm{III}_{\mathrm{b}}$, and are designed according to Appendix A of the Mexico City Building Code (RDF-04), for a soil dominant period of $\mathrm{T}_{\mathrm{s}}=2$ seconds, satisfying the maximum service and collapse limit states for story distortion. Resistances were designed taking into account a three-dimensional structural performance in addition to the vertical load effects and second order effects. Due to the use of seismic performance factors $(\mathrm{Q}=4$ for the 6-story building and $\mathrm{Q}=3$ for the 17 story building), and according to the Concrete Construction Standard, special requirements were considered for the ductile frame. Nominal resistance and over-resistance effects were considered for the non-linear responses. Different inputs of lateral load patterns for the non-linear static analysis were taken into account. The comparisons were performed for base shear force-roof lateral displacement relations, global distribution of plastic hinges, failure mechanics tendency, local and global ductility demands, etc.

Keywords: spectral modal dynamic analysis, non-linear static analysis, inelastic seismic analysis.
\end{abstract}




\section{Introduction}

This work determines and compares both, the non-linear seismic behavior (PushOver) and the dynamic inelastic step by step behavior, of a 6- and a 17-story office building with reinforced concrete (RC) frames, located in the compressible zone of Mexico City. The design was made according to the service and failure limit states of the Mexico City Building Code (RDF-04, 2004), established in its corresponding Seismic and Concrete Complementary Technical Standards (NTC-Seismic, NTC-Concrete) [1]. The structures were designed as follows: A) with the design spectrum of the Main Text of the NTC-Seismic (seismic zone $\mathrm{III}_{\mathrm{b}}$ ); and $\mathrm{B}$ ) with the design spectrum according to the soil dominant period, defined in the Appendix A of the NTC-Seismic ( $\mathrm{T}_{\mathrm{s}}=2$ seconds). The timehistory inelastic seismic responses were analyzed with representative records of maximum compressible soil damage in Mexico City obtained from the earthquake of September, 1985. For the Push-Over analyses, the responses under different lateral load distributions were obtained as well as the collapse mechanisms, the base shear force-roof lateral displacement curves and the maximum demands of local and global ductility. The influence of the possible over-resistance sources was included. From the results of this work it is to be noticed that there are no important variations between Main Text and Appendix A cases. Appendix A criterion allows to determine the displacement of the service and collapse conditions to which the structure may be subjected to.

\section{Elastic response calculation}

\subsection{Description of the structures and design procedure}

The studied structures correspond to office buildings of 6 and 17 stories of reinforced concrete, symmetric and regular in plan and elevation. They have a foundation rigid box. The 17-story building has point piles. The concrete is class 1 with $\mathrm{f}^{\prime}{ }_{\mathrm{c}}=250 \mathrm{~kg} / \mathrm{cm}^{2}$ and elastic modulus $E_{c}=14,000$ times square root of $\mathrm{f}^{\prime}$, and the longitudinal and transverse steel with $\mathrm{f}_{\mathrm{y}}=4,200 \mathrm{~kg} / \mathrm{cm}^{2}$. The structural system is composed of reinforced concrete frames with girders and columns rigidly connected by a solid slab of $10 \mathrm{~cm}$ thick. Fig. 1 shows the main details in plan and elevation of the studied buildings. The column and girder resistances were designed for the last mechanic elements of the spectral modal dynamic analysis, considering the three-dimensional structural performance plus the vertical load effects (dead loads and live loads) and second order effects. For the ductile frame special requirements were considered as it is established in the Concrete Standards, due to the use of seismic performance factors $Q=4$ for the 6-story building, and $\mathrm{Q}=3$ for the 17-story building.

\subsection{Vibration periods}

Table 1 compares the three periods of vibration modes (X, $\mathrm{Y}$ and $\theta$ directions) of the 6- and 17-story buildings, respectively. There are no differences between 

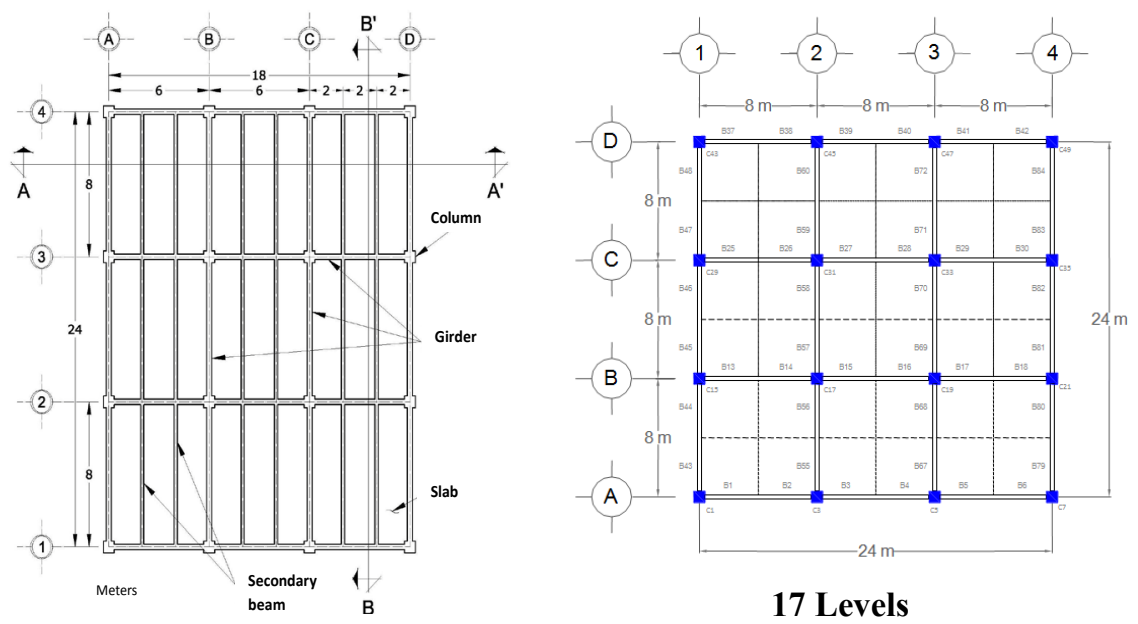

6 Levels
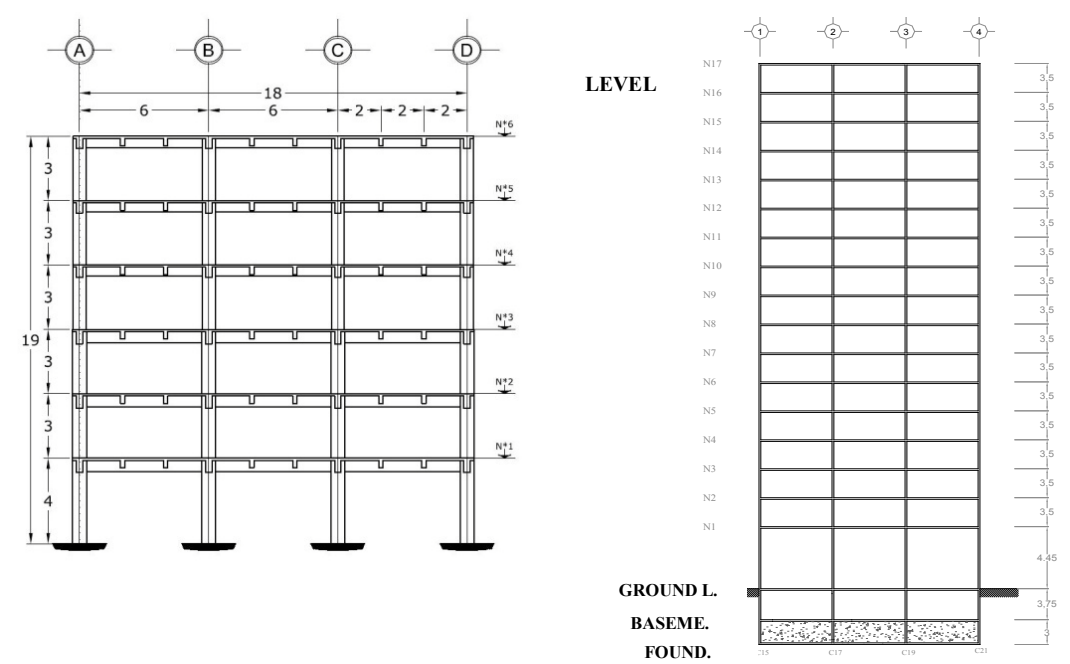

Figure 1: Structural plant-type (dimensions in meters) and transversal cuts of 6-story and 17-story buildings.

Main Text and Appendix A cases, as expected. For the 17-story building, due to symmetry in the structure, the periods in the $\mathrm{X}$ and $\mathrm{Y}$ directions are the same. Figs 2 and 3 show the design spectra of the RDF-04 of the Main Text (seismic zone $\left.\mathrm{III}_{\mathrm{b}}\right)$ and the Appendix $\mathrm{A}\left(\mathrm{T}_{\mathrm{s}}=2\right.$ seconds), the elastic and inelastic response spectra of the record SCT-EW-85 (critical viscous damping of 5\%) as well as the location of the fundamental periods of vibration of the 6-story $\left(\mathrm{T}_{1 \mathrm{x}}=0.832\right.$ seconds) and 17-story buildings $\left(\mathrm{T}_{1 \mathrm{x}}=1.752\right.$ seconds $)$ in the $\mathrm{X}$ direction. 
Table 1: $\quad$ Vibration periods of 6-story and 17-story buildings.

\begin{tabular}{|c|c|c|c|c|c|c|}
\hline \multicolumn{7}{|c|}{ Vibration periods, $T_{i}$ (seconds) } \\
\hline \multirow{2}{*}{ Direction } & \multicolumn{3}{|c|}{ 6-story } & \multicolumn{3}{|c|}{ 17-story } \\
\hline & $\mathrm{T}_{1}$ & $\mathrm{~T}_{2}$ & $\mathrm{~T}_{3}$ & $\mathrm{~T}_{1}$ & $\mathrm{~T}_{2}$ & $\mathrm{~T}_{3}$ \\
\hline $\mathrm{X}$ & 0.832 & 0.279 & 0.138 & 1.752 & 0.643 & 0.374 \\
\hline $\mathrm{Y}$ & 0.837 & 0.278 & 0.138 & 1.752 & 0.643 & 0.374 \\
\hline$\theta$ (torsion) & 0.676 & 0.228 & 0.114 & 1.346 & 0.518 & 0.306 \\
\hline
\end{tabular}

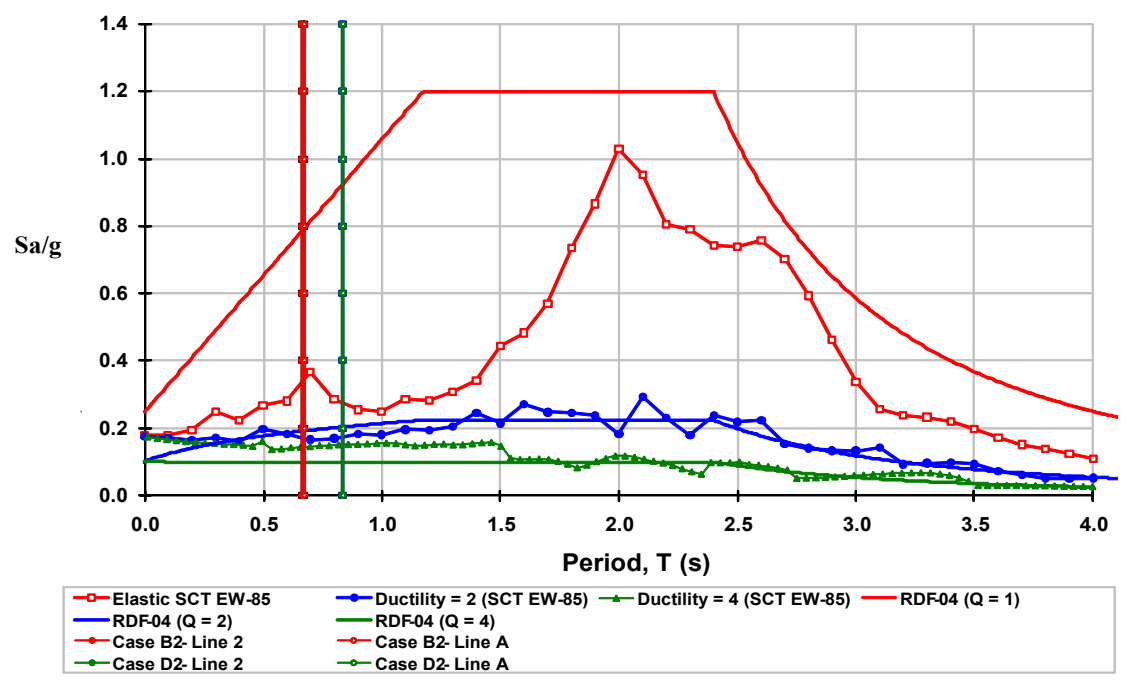

Figure 2: Location of fundamental period of vibration of 6-story structure, regarding the design spectra $(\mathrm{Q}=1$ and 4$)$ and the response spectra $(\mu=1$ and 4$)$ of SCT-EW-85 record.

\subsection{Maximum story drifts}

The 6-story building under earthquake in both directions, accomplishes with the permissible limit of 0.006 specified in the main text, and with the permissible limit of 0.002 for Appendix A. The collapse limit of 0.03 was not a governing condition for the performance of the design. The 17-story building accomplishes with both permissible limits, being slightly above the service condition of Appendix A.

\section{Calculation of the inelastic dynamic response}

Inelastic dynamic responses step-by-step are determined by using the E-W SCT accelerogram, registered on September $19^{\text {th }}$ of 1985 . The responses were 


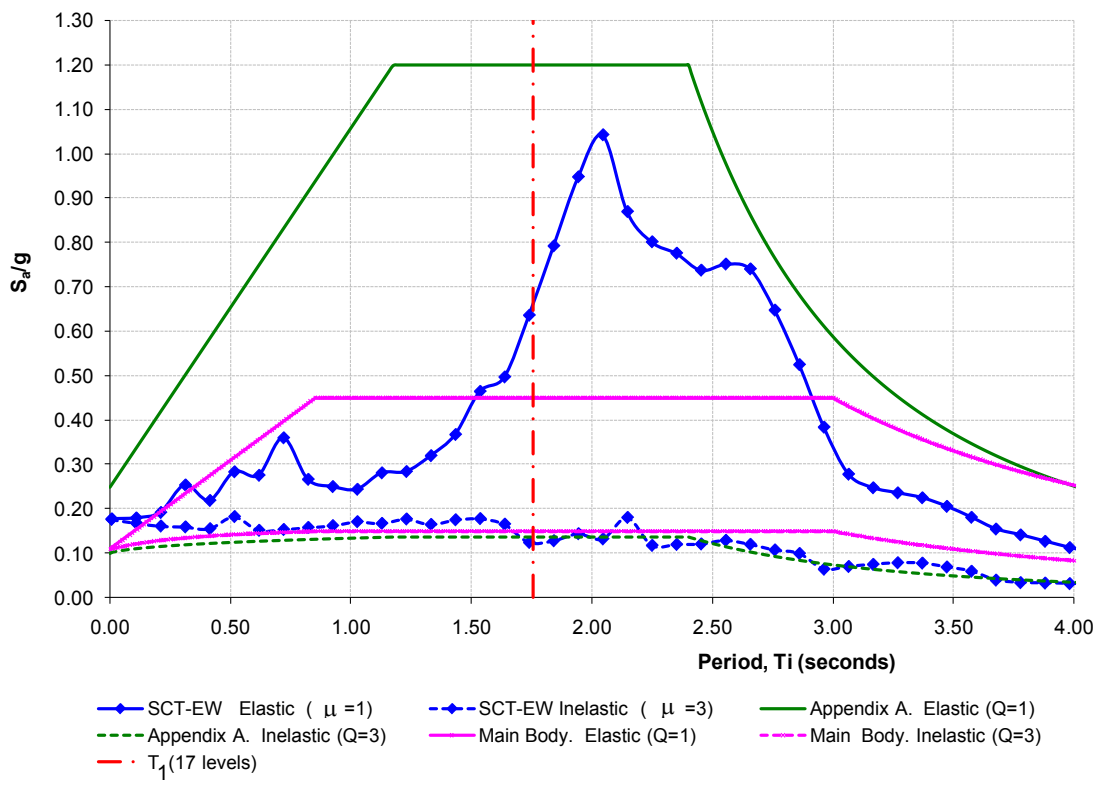

Figure 3: Location of fundamental period of vibration of the 17-story structure, regarding the design spectra $(\mathrm{Q}=1$ and 3$)$ and the response spectra $(\mu=1$ and 3$)$ of SCT-EW-85 record.

calculated for the axes 2 (X direction) and $\mathrm{A}$ ( $\mathrm{Y}$ direction) of the 6-story building, and axes $\mathrm{C}$ and $\mathrm{B}$ for the 17-story building (see fig. 1), respectively. The corresponding frames were "calibrated" to ensure static and dynamic behavior similar to the three-dimensional model.

\subsection{Global ductility maximum demands, $\mu_{G}$}

All buildings, with nominal resistances, experimented inelastic performance; generally, with over-resistance effects, having lower global ductility demands. In no case $\mu_{\mathrm{G}}$ was over the values of 4 or 3 , which are equal to the values of the seismic performance factor (Q) for which the elastic design spectra were reduced (see table 2).

\subsection{Curves of base shear force-roof lateral displacement}

When inelastic behavior is present, it is observed that, as the structure dissipates more amount of seismic energy, the responses have more hysteretic area, and there are further reductions in the base shear force and the roof horizontal displacement. Figs. 4 and 5 compare the curves of base shear force-roof lateral displacement of the 6- and 17-story buildings under elastic and inelastic step-bystep seismic analysis with nominal and over-resistances. The hysteretic curve of the 6-story model with nominal resistances is slightly wider, which means a lightly larger incursion in the nonlinear range and higher energy dissipation. The 
Table 2: $\quad$ Calculated global ductility maximum demands of 6- and 17-story buildings under inelastic step-by-step seismic analysis with nominal and over-resistances.

\begin{tabular}{|c|c|c|c|c|c|c|}
\hline \multicolumn{4}{|c|}{ Nominal resistance } & \multicolumn{3}{|c|}{ Over-resistance } \\
\hline Levels & $\begin{array}{c}\Delta_{\mathrm{Y}} \\
(\mathrm{cm})\end{array}$ & $\begin{array}{c}\Delta_{\max } \\
\text { inelastic } \\
(\mathrm{cm}) \\
\end{array}$ & $\mu_{\mathrm{G}}$ & $\begin{array}{c}\Delta_{Y} \\
(\mathrm{~cm})\end{array}$ & $\begin{array}{c}\Delta_{\max } \\
\text { inelastic } \\
(\mathrm{cm})\end{array}$ & $\mu_{G}$ \\
\hline $6(Q=4)$ & 5.23 & 18.44 & 3.53 & 5.16 & 5.91 & 1.15 \\
\hline $17(\mathrm{Q}=3)$ & 19.24 & 42.85 & 2.23 & 29.01 & 47.01 & 1.62 \\
\hline
\end{tabular}

$\mu_{\mathrm{G}}=\Delta_{\text {max inelastic }} / \Delta_{\mathrm{Y}} ; \Delta_{\mathrm{Y}}=$ roof lateral displacement for the first yield.

$\Delta_{\text {max inelastic }}=$ roof maximum lateral displacement for the inelastic performance.
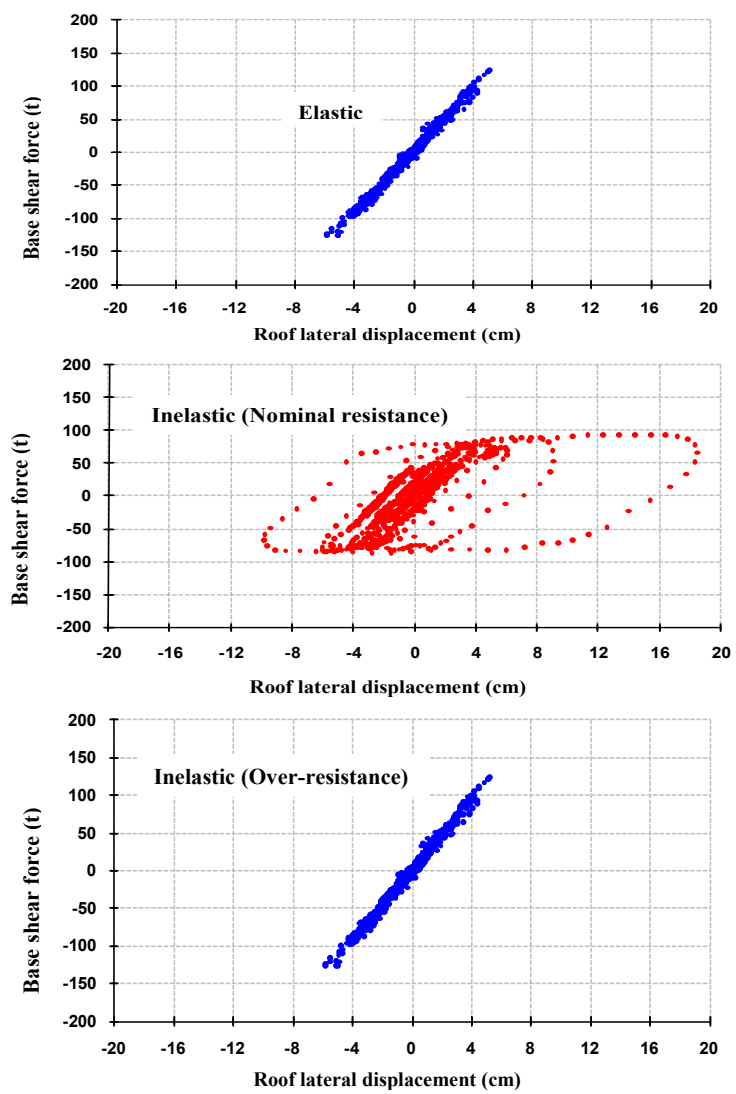

Figure 4: Curves of base shear force-roof lateral displacement, elastic and inelastic step-by-step seismic analysis (nominal and overresistances), 6-story structure. 

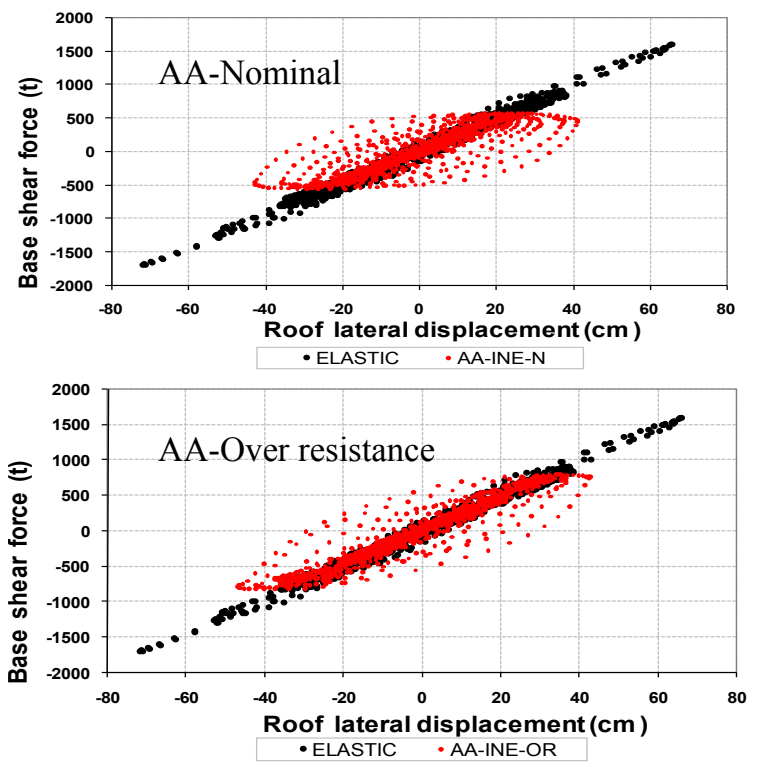

Figure 5: Curves of base shear force-roof lateral displacement, elastic and inelastic step-by-step seismic analysis (nominal and overresistances), 17-story structure.

17-story models tend to have a larger hysteretic area, and over-resistance cases show a slight inelastic behavior, although on a less important way than the condition of nominal resistance.

\subsection{Global distribution of plastic hinge and demands of local ductility}

The overall distribution of plastic hinges for all the structures had a general tendency to the failure mechanism known as the "beam" type; this means that the plastic hinges are present in most of the beams, and only in some columns, which is consistent with the design philosophy of "strong column-weak beam" of the RDF-04 code. Fig. 6 has global distributions of plastic hinges on the 17-story building without and with over-resistances. Colors described different times in which each plastic hinge was introduced from blue color in the beginning until the end of the most intensive phase of the record SCT-EW-85. Fig. 7 shows the maximum local ductility demands developed in beams, for Main Text and Appendix A conditions of the studied 17-story building; columns behave almost in the elastic range, with maximum demands less than 1.5. The maximum demands for the nominal cases present values between 4 and 6 in beams, whereas in columns, the values are less than 2; with the over-resistance effects, such that the maximum demands in beams are from 2 to 3 and columns behave elastically, for practical purposes. The maximum value in beams in the 17-story building varies between 3 and 7 with nominal resistance and between 1.5 and 3 when over-resistance effects are considered. 


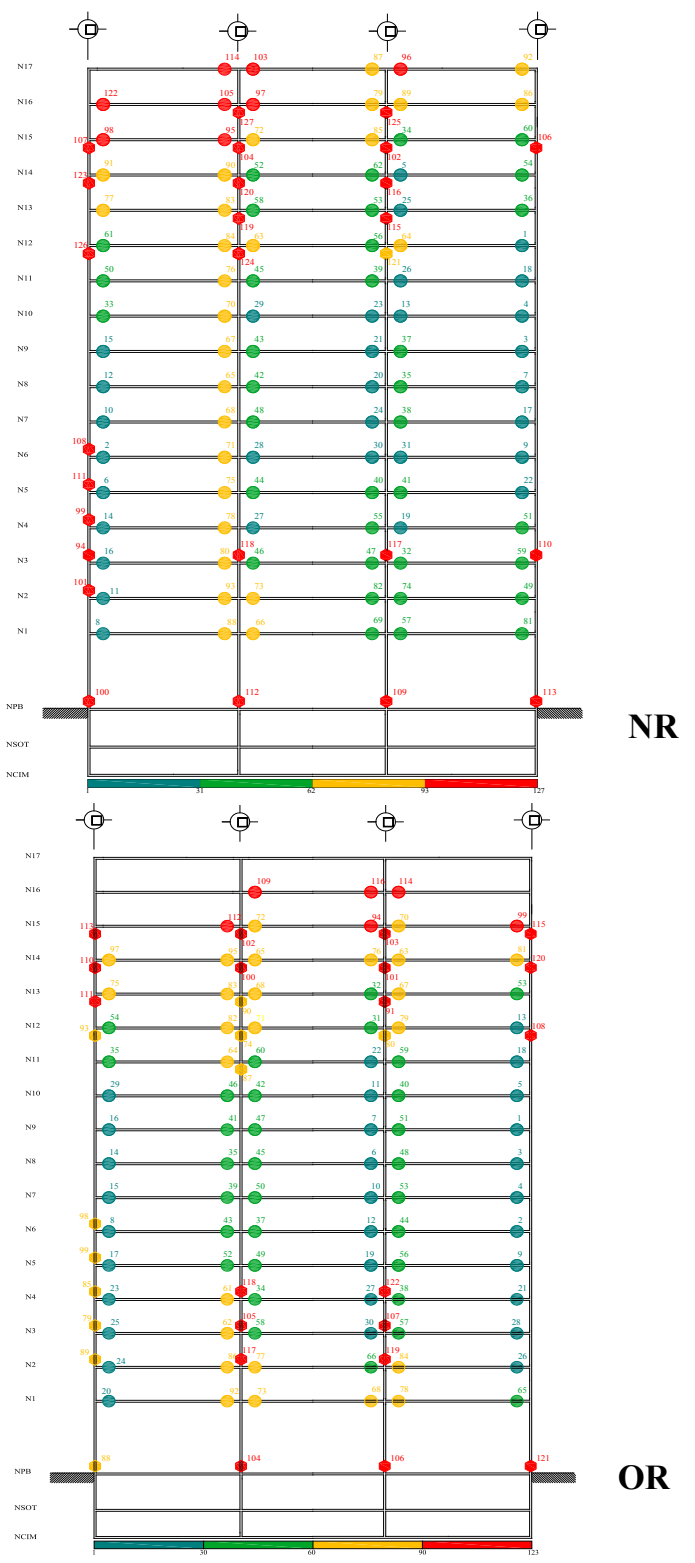

Figure 6: Apparition sequence and global distribution of plastic hinges, 17story structure, with nominal resistances (NR) and over-resistances (OR) effects. 


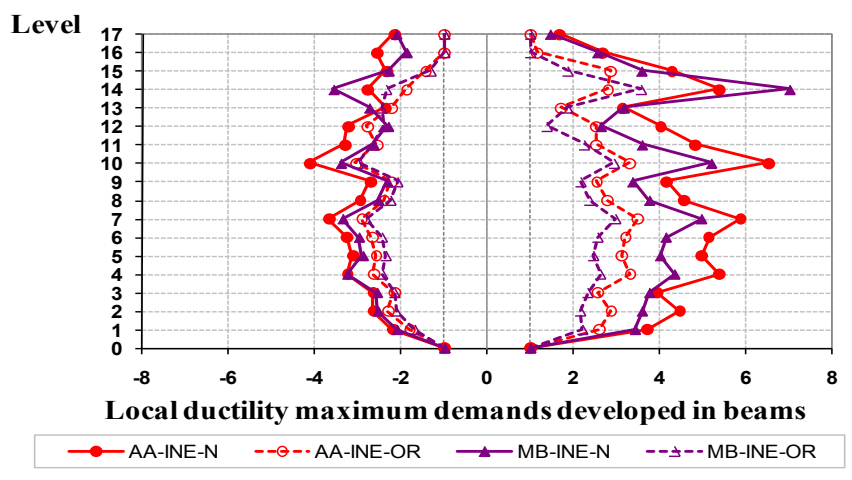

Figure 7: Local ductility maximum demands developed in beams, inelastic step by step analysis with nominal resistances $(\mathrm{N})$ and overresistances (OR), 17-story building, Main Text and Appendix A designs.

\section{Non-linear static analysis (Push-over)}

The non-linear static analysis with four different distributions of lateral load, were made with and without the over-resistance effects, to know: 1) SMD distribution with forces at the floor level $\left(\mathrm{F}_{\mathrm{i}}\right)$, determined from the story shear forces $\left(\mathrm{V}_{\mathrm{i}}\right)$ of the spectral modal dynamic analysis, involving all modes of lateral vibration; 2) Elastic step-by-step distribution with forces at floor level $\left(\mathrm{F}_{\mathrm{i}}\right)$, calculated with the story shear forces $\left(\mathrm{V}_{\mathrm{i}}\right)$ for a " $\mathrm{t}_{\mathrm{i}}$ " time from an step-by-step analysis, when the structure is working in the elastic range; 3) Inelastic step-bystep distribution with forces at floor level $\left(\mathrm{F}_{\mathrm{i}}\right)$, defined with the story shear forces $\left(\mathrm{V}_{\mathrm{i}}\right)$ for a " $\mathrm{t}_{\mathrm{i}}$ " time from a step-by-step analysis when the structure the maximum inelastic roof displacement is shown; 4) Linear triangular distribution from $F_{i}$ forces as a result of the hypothesis of static seismic analysis (linear). Fig. 8 shows the lateral load distributions for the non-linear static analysis (Push-over) of the 17-story building. The results shown are only for the case in which the distributions are obtained from a spectral modal dynamic analysis (SMD), with the participation of all modes of lateral vibration. The Push-over analyses were made to the following conditions: a) maximum demands of the local ductility in beams are equal to 35, b) maximum demands of the local ductility in columns are equal to 20, c) maximum story drift of the collapse condition is 0.03 , according to Appendix A of the NTC-Seismic of RDF-04 Code for structures for ductile concrete frames with $\mathrm{Q}=3$ or $4, \mathrm{~d}$ ) the mechanism of collapse of the structure is reached.

\subsection{Curves of base shear force-roof lateral displacement}

Figs. 9 and 10 compare the results of the base shear force-roof lateral displacement relationships of the Push-over analyses against relationship of the corresponding inelastic step-by-step analyses without and with over-resistance 


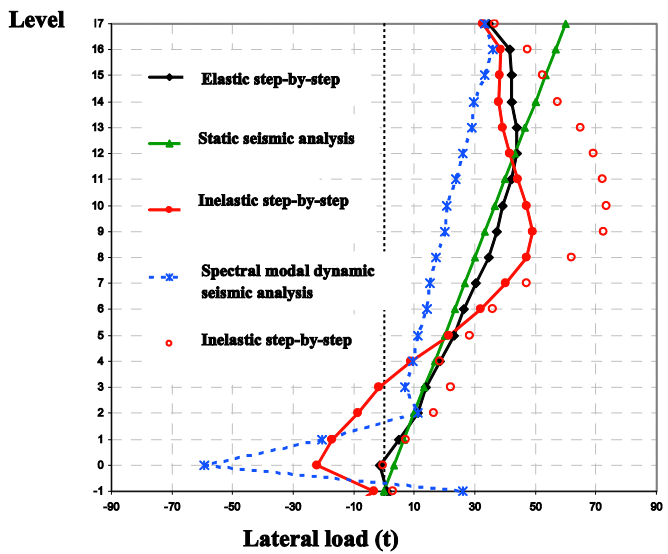

Figure 8: Lateral loads distributions for the non-linear static analysis (Pushover), 17-story building.

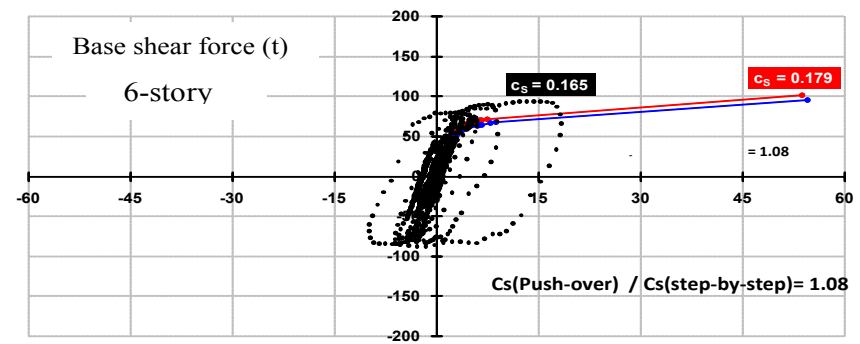

Roof lateral displacement $(\mathrm{cm})$
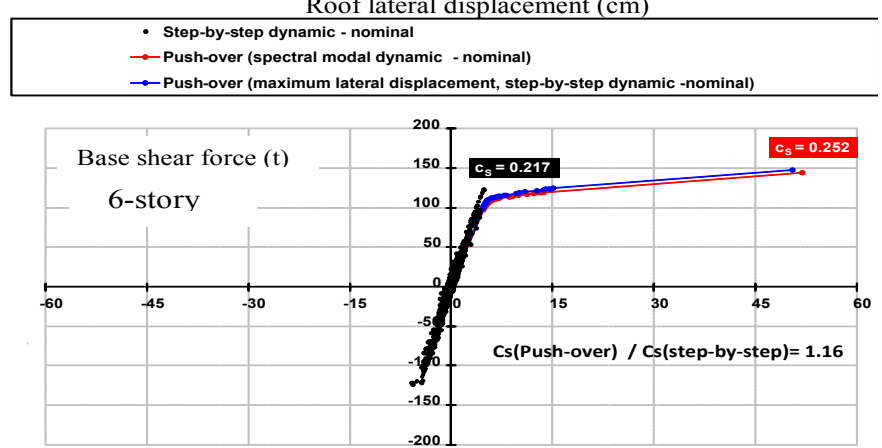

Roof lateral displacement $(\mathrm{cm})$

- Step-by-step dynamic over-resistance

- Push-over (spectral modal dynamic over -resistances)

- Push-over (maximum lateral desplacement, step-by-step dynamic over -resistances)

Figure 9: Curves of base shear force-roof lateral displacement comparison, non-linear static analysis (Push-over) and inelastic step-by-step dynamic analysis with nominal resistance and over-resistances effects, 6-story structure. 


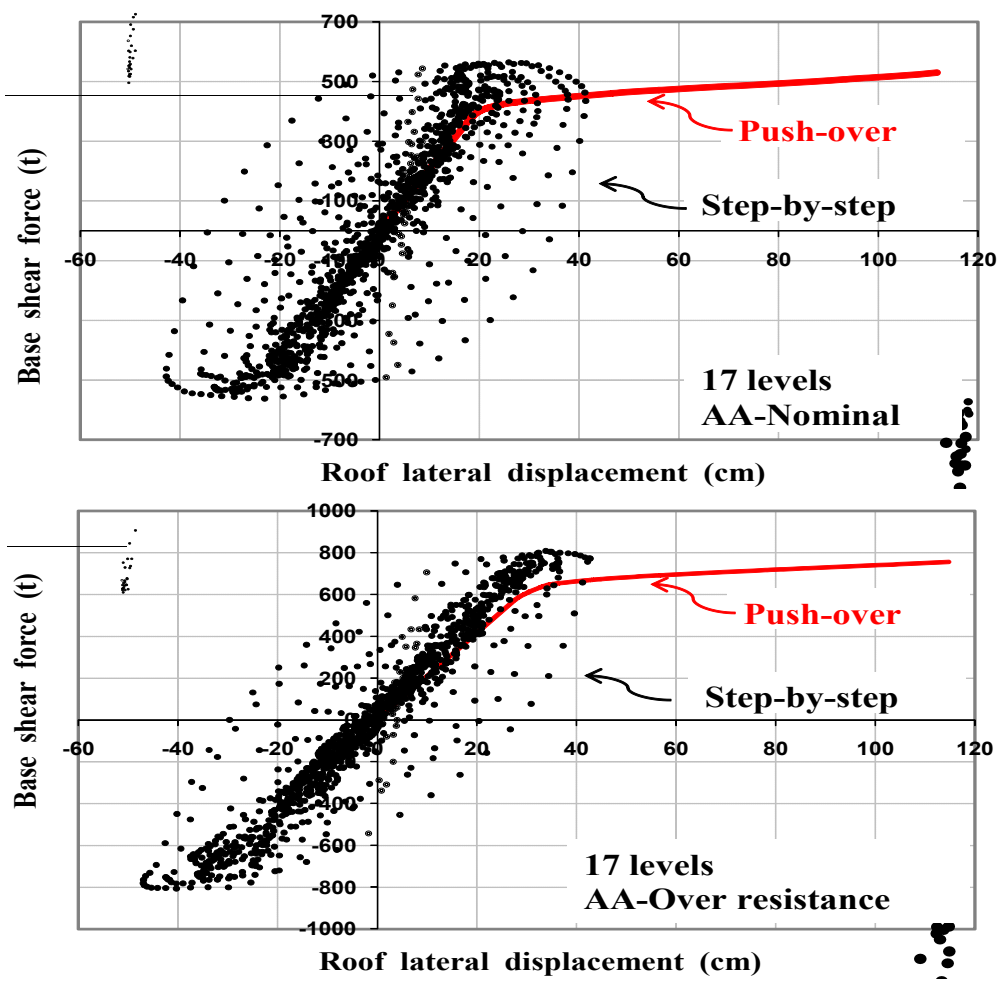

Figure 10: Curves of shear force-roof lateral displacement relationships comparison, non-linear static analysis (Push-over) and inelastic step-by-step dynamic analysis with nominal resistance and overresistances, 17-story structures.

effects, of the 6- and 17-story models, designed with Appendix A. For 6-story models, the resulting performance from Push-over analysis was governed generally by the condition of permissible drift of collapse of 0.03 . For 17 -story models, the resulting behavior from Push-over analysis was governed generally by the condition of permissible drift of collapse of 0.03 . The influence of overresistance effects is very important. The results of both types of analysis, confirm the lateral stiffness and lateral resistance of each structure as well as their capacity of energy dissipation facing the typical seismic effects of Mexico City.

\section{Conclusions}

Buildings designed with the Seismic Technical Standards of the Mexico City Building Code (RDF-04) show satisfactory performance, with sufficient resistance reserve, to avoid brittle failure. Significant variations between the designs of the Main Text and Appendix A conditions are not presented. With the help of the over- resistance effects, the maximum responses tended to be 
108 Earthquake Resistant Engineering Structures IX

lower. The tendency of plastic hinges from step-by-step and non-linear static (Push-over) analyses show, in general, a strong column-weak girder performance according to the current design philosophy, which ensures a ductile behavior. The Push-over analysis results show consistency regarding to responses of dynamic analysis in time history.

\section{References}

[1] Gaceta Oficial del Gobierno del Distrito Federal (2004), "Reglamento de Construcciones de la ciudad de México y Normas Técnicas Complementarias" 